\title{
Research Paper: A Behavioral Intervention for Changing the Attitude of Young Boys in Iranian Juvenile Detention Centers
}

\author{
Seyyed Mohammad Hossein Javadi ${ }^{1} \oplus$, Lotfollah Mohseni ${ }^{2} \oplus$, Iraj Esmaili ${ }^{3}$, Ataollah Mohamadi ${ }^{4} \oplus$, Hamed Seddighi $^{5}$, Seyyed Hadi \\ Mousavi $^{3}$
}

1. Social Work Department, University of Social Welfare and Rehabilitation Sciences, Tehran, Iran

2. Assosiation of Community Services Volunteers for Released Prisoners (Madadyaran), Tehran,Iran.

3. Substance Abuse and Dependence Research Center, University of Social Walfare and Rehabilitation Sciences, Tehran, Iran

4. Center of Counselling, Tehran University, Tehran, Iran.

5. Student Research Commitee, University of Social Welfare and Rehabilitation Sciences, Tehran, Iran.

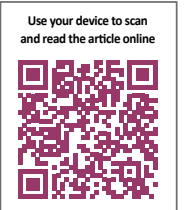

chtation: Javadi SMH, Mohseni L, Esmaili I, Mohamadi A, Seddighi H, Mousavi SH. A Behavioral Intervention for Changing the Attitude of Young Boys in Iranian Juvenile Detention Centers. Iranian Rehabilitation Journal. 2019; 17(3):241-252. http:// dx.doi.org/10.32598/irj.17.3.241

http://dx.doi.org/10.32598/irj.17.3.241

Article info:

Received: 02 Jan 2019

Accepted: 28 May 2019

Available Online: 01 Sep 2019

\section{Keywords:}

Juvenile delinquency, Behavioral intervention, Adolescent, Intervention research

\section{A B STRACT}

Objectives: Delinquency is one of the severe social problems. Today, changing criminal behavior and reducing the way and method of delinquency is one of the most important challenges in the juvenile justice system.

Methods: Based on the cognitive-behavioral approach, this study used three principles of Red Cross and Red Crescent fundamental principles, three skills of basic life skills, and first aid skill. A group intervention in 13 sessions was designed for changing the attitudes of juveniles in conflict with the law and was implemented in juvenile detention centers in 5 provinces. Then, the efficiency of the model was evaluated. In this quasi-experimental study, two groups were compared as the pre-test, and then post-test. The statistical sample contained 127 boys with the age range of 12 to 19 years, who were randomly selected among delinquent juveniles in the mentioned centers. The reliability and validity of the researcher-made and normalized questionnaires were examined and confirmed by the opinions of experts and statistical methods.

Results: There were significant differences between the experimental and control groups in humanity, impartiality, and voluntary services as well as the sum of fundamental principles and first aid skills, self-awareness, problem-solving, and anger management scores. These significant differences suggest that the model can develop these scores.

Discussion: This model is effective in improving knowledge and skills and changing the attitude of delinquent juveniles. Based on the findings of this study, a model was designed, using three principles of the Red Cross society, basic life skills, and first aid skills that can be effective in changing the attitudes and behavior of people in the juvenile detention centers. This finding is consistent with the studies and similar experiences at this level and requires additional longitudinal studies to investigate its effects on the frequency of recidivism, arrest, trial, and return to the center or imprisonment.

\footnotetext{
* Corresponding Author:

Lotfollah Mohseni, MA.

Address: Assosiation of Community Services Volunteers for Released Prisoners (Madadyaran), Tehran, Iran.

Tel: +98 (912) 2197365

E-mail:lmohseni@yahoo.com
} 


\section{Highlights}

- Adolescents in conflict with the law need behavioral change interventions.

- Interventions implemented by humanitarian organizations in adolescent detention centers can be effective.

- Humanitarian concepts and life skills are effective in changing the behavior of adolescent in conflict with the law.

\section{Plain Language Summary}

Today, changing criminal behavior and reducing the way and method of delinquency are among the most critical challenges in the juvenile justice system. Based on the cognitive-behavioral approach, this study used three principles of Red Cross and Red Crescent societies, including humanity, impartiality, and voluntary services, as well as three basic life skills, and first aid principle. A group intervention in 13 sessions was designed for changing the attitudes of juveniles in conflict with the law and was implemented in juvenile detention centers in 5 provinces in Iran. Then, the efficacy of the model was evaluated. According to the results, this model was effective in improving knowledge, skills, and attitudes of delinquent juveniles.

\section{Introduction}

tatistical surveys and studies confirm the increasing number of adolescents in conflict with the law. The reports of the national juvenile detention centers show a significant increase in young delinquents, and the continuation of this procedure can be very concerning. Children are one of most vulnerable group in a society and Typically, in developing countries, children hold a high percentage of the population [1].

Considering the juvenile delinquency in Iranian society and because of the young population structure of the country, the process of quantitative and qualitative changes should be discussed with more details. The timely and appropriate interventions and management of childhood and adolescent behaviors can prevent the persistence of delinquency and change the course of criminal behavior.

Today, changing criminal behavior and reducing the way and method of delinquency is one of the most important challenges in the juvenile justice system. A large number of studies have reported empirical evidence of the significant effects of interventions on these behaviors and compared interceptive approaches and introduced the most effective ones [2]. Many options for remedial treatment of adolescents can be divided into two main categories; social-based and institutional treatment. Social-based treatment is intended to provide care, support, and treatment for the needs of adolescents in the community [3].
In non-planetary programs, adolescents remain at home but are being consulted, receive professional education, or other services. Institutional treatment is the juvenile detention centers run by the government. In these institutions, the residents' activities are monitored by caregivers, the external shells are locked, and internal shells are protected by grid fences. Many studies have shown that punishment alone cannot be an effective means of preventing the recurrence of juvenile offenders $[4,5]$. Various measures are being taken within the juvenile detention centers. It is difficult to choose the appropriate method for correcting adolescents in conflict with the law.

Almost all of the centers present counseling, psychological interventions, occupational interventions, vocational education, recreational programs, religious counseling, medical treatment programs, and legal services and cases [6]. The goal of these programs is the rehabilitation of adolescents. The precise evaluation of community-based interventions and parenting centers has shown that treated adolescents have a $10 \%$ lower reoffending rate than those who failed to receive these services. Similarly, the programs that are best done, and in which offenses are repeated between $20 \%$ and $30 \%$, have decreased.

The most successful therapeutic programs have been designed such that to improve interpersonal skills, selfcontrol, and academic achievement. Programs with a psychological orientation, such as individual, group, and family counseling have a modest positive impact on adolescents. The effective individual treatment pro- 
grams are a combination of psychotherapy, reality therapy, and behavior change. Individual counseling is one of the most commonly used treatments, and it is widely used in almost all educational and training centers. Not only individual counseling does not seek to change the personality of the adolescent, but also it strives to help adolescents understand and solve their current adaptive problems.

Group therapy is one of the most cost-effective treatments for individual therapy. Group psychosocial, guided group interaction, positive peer culture, and milieu therapy programs all belonged to group therapy. These types of programs are not solutions for all problems. Teens need to obtain a variety of skills to give them hope. It seems that therapeutic programs that have the greatest effect on rehabilitation in juvenile offenders are those that use a combination of methods. Comprehensive programs that increase adolescents' capacity and social orientation are more likely to succeed.

By focusing on problematic behaviors and maladaptive thinking patterns, cognitive-behavioral interventions, either individually or collectively, have become one of the major interventions in various correctional institutions. In corrective educational institutions, psychologists are more likely to use cognitive-behavioral therapy to modify antisocial and non-social behavioral and intellectual patterns in society, so that disorders are likely to be less related to their criminal and destructive behaviors [7]. This approach is both practical and effective because cognitive-behavioral models have shown positive effects in the short-term treatment of violent offenders and inmates [8].

Seto and Barbaree argued that cognitive-behavioral therapy, combined with the training of social skills, had also been useful for the treatment of sexual offenders, reducing anxiety, and improving their self-esteem [9]. Lösel and Schmucker reported the rate of reprisals in the group treated with this method in comparison with the control group [10]. Therefore, cognitive-behavioral therapy has been introduced as a major component of interventions and effective treatments for offenders, including adolescents $[4,5,11,12]$. In the context of cognitive-behavioral training in improving social cognitive skills with Social Skills Training (SST), Serna et al. have shown the effectiveness of this method in reducing criminal behavior by reviewing 30 studies on delinquent and aggressive juvenile offenders, using "Aggression Replacement Therapy" (ART), working with anxiety disorder, children with a multidisciplinary and comprehensive Reasoning and Rehabilitation ( $\mathrm{R} \& \mathrm{R}$ ) and the studies on the services related to curative treatment programs in Canadian criminals [13-18]. A meta-analysis of 69 cognitive-behavioral programs conducted by Wilson (2005), a meta-analysis of 58 studies and a meta-analysis reviewing 20 studies in this area have also shown the effectiveness of cognitive-behavioral therapy $[19,20]$.

Generally, due to the numerous studies carried out in the domain of cognitive-behavioral interventions, it is worth mentioning that multimodal interventions may be considered the most appropriate method due to the heterogeneity of criminals. Therefore, according to the author's experiences, the present proposal has used a hybrid model for its intervention model. Firstly, it uses a cognitive-behavioral approach based on three principles of the Red Cross and the Red Crescent Society (humanity, impartiality, and voluntary services), three skills of essential life skills (self-awareness, anger management, and problem-solving skills), and first aid and relief skills. Then, the effectiveness of this intervention model was assessed. This study aimed to examine the effectiveness of its intervention model in changing the attitudes and behavior of the children in conflict with the law of the resettlement centers.

\section{Methods}

The present study is quantitative based on the nature of the collected data and applied in terms of the objective and quasi-experimental in terms of methodology. The layout of the proposed design is pre-test and post-test with the randomized controlled trial. This in-depth study is also a kind of low-level study that seeks to generalize the results of a small sample of the population to the population as a whole.

The statistical population of this study is the adolescents in conflict with the law in the Detention centers of five provinces of Iran: Tehran, Alborz, Khorasan Razavi, Khuzestan, and Sistan and Baluchestan. The sample consisted of 127 adolescent boys, who were offended by the law of resettlement centers; they were studied according to inclusion and exclusion criteria. The case group was selected through probable sampling and, then, randomly divided into intervention and comparison groups. In the Sistan and Baluchistan juvenile detention centers, where the number of clients was low, all clients were used. Of the 127 cases in the two groups, 35(27.6\%) people were from Alborz, 19(15\%) from Khorasan Razavi, 39(30.7\%) from Khuzestan, 12(9.4\%) from Sistan and Baluchistan, and 22(17.3\%) from Tehran. 
The authors of this plan believed that unhealthy and ineffective attitudes of children and adolescents in conflict with the law could be changed, using the concepts inherent in the fundamental principles of the Red Cross and the Red Crescent. In addition to this potential and due to the general weakness of this group in the life and social skills, three skills of basic life skills were added to these concepts. The operational and related component of this model was completed with social behaviors, using first aid education and relief. This model includes 13 sessions, each of which is run in two sections for 4 hours.

To implement the designed model, at first, we trained 90 volunteers from the Red Crescent Youth Organization and the Prisons Organization in three workshops in Tehran and Mashhad for three days. Then, 30 of them were selected, and in the second workshop, they were trained and followed-up with the model and the method of its implementation and education. The educational package includes a trainer's guide, instructions, the full text of the model, the program of change attitude, questionnaires, and evaluation forms. Subsequently, the implementation team and evaluation team supervised and set up the provincial programs.

The various indicators are commonly used to assess the effectiveness of rehabilitation programs at juvenile detention centers. The evaluation of this intervention model also requires different indicators. Considering the objectives of the model, the knowledge, skills, attitudes, and behavior changes must be evaluated.

To assess the change in knowledge, skills, and attitude of the offenders participating in the project, valid and reliable questionnaires (researcher-made and prepared) were used before and after the intervention. These tools include five questionnaires that measure self-awareness skills, problem-solving, anger control, participants' attitudes toward humanity, impartiality, voluntary service; and measuring self-relief and other relief skills.

For the design of the questionnaire, at first, 120 entries were prepared related to the concepts of the fundamental principles of the Red Cross. Of these phrases, 85 terms were selected that could be effective in measuring attitudes. Subsequently, these terms were given to 20 senior authorities of the Red Crescent Youth Organization to assess their content validity, and 38 comments were selected based on expert opinions.

Three validated questionnaires for measuring life skills were added to the test; self-awareness, problem-solving, and anger management. A total of 10 questions were added to the collection of knowledge and skill tests of the Youth Initiatives Aid. A demo sample was added to the collection for demographic assessment. To assess the reliability of the instrument, the tool was completed in two rounds and 15 days interval by using the juvenile detention centers in Tehran Province. Using statistical and test methods, its validation was confirmed, and unstable items were removed from the list. To assess the validity of the questionnaire, Cronbach's $\alpha$ was calculated in three steps. This comparison process between the means and the significant test of the difference between the meanings for the two groups of the control and the subjects in the three stages of the pre-test, post-test and the follow up with a 15-day interval, which summarizes the results in (Table 1) is observed.

Another indicator is the condition of the youth delinquents' behavior during the stay in the center. The degree of adaptation, conventional and unusual behaviors, aggression, and the degree of academic and professional progress of the patient are assessed, using the checklist provided to the staff. The implementation of this assessment requires the training of employees, and, in particular, the care and training of carers, and educators group.

The third indicator is the rate of committing a crime and re-arrest, which must be reviewed, recorded, and evaluated at intervals of three months, six months, one year, and three years after the discharge.

Finally, the quality of life indicator is one of the most useful indicators. To achieve this index, a checklist is also provided, which were completed three months, six

Table 1. The results of the reliability test of the questionnaire with the Cronbach's a

\begin{tabular}{cccc}
\hline Indicators Test & Absolute Flood & Item & Cronbach's $\boldsymbol{\alpha}$ \\
\hline Pre-test & 127 & 64 & 0.904 \\
Post-test & 127 & 64 & 0.951 \\
Follow-up & 74 & 64 & 0.836 \\
\hline
\end{tabular}


months, one year, and three years after leaving the center. It included satisfaction with life, family status, higher education, employment, substance use status, and alcohol, and the degree of family satisfaction of the youth delinquents' behavior is evaluated, registered, and analyzed. In this phase of the project, due to limitations, only one questionnaire was designed to assess the attitude change, knowledge, and skill of the subjects was used.

Based on what was predicted in the model, the effectiveness of the model was evaluated, using a researchermade test in three stages; pre-test, post-test (immediately after the completion of the intervention), and follow up test (two weeks after the completion of the intervention). The second one was performed in the two experimental and control groups. Because of the time intervals, other indicators can be determined over longer periods.

Given that the number of phrases or questions in all dimensions and their components are not equal, the standard scores should firstly be calculated in each case. For this purpose, the following scores were converted to the standard scores by the formula; in the statistical calculations, the standard scores were normal. Of course, the First Aid Department contained 10 questions; total grade was 100 , and it was not necessary to standardize it.

The data from three stages of the standardized test and scores were analyzed, using SPSS V. 22 and parametric $\mathrm{t}$ test in the two independent groups. To use the parametric test, first, the Kolmogorov-Smirnov test was used to confirm the normal distribution of the data. Then the Pearson correlation coefficient was used to examine the correlation between the studied variables.

\section{Results}

The age distribution of the sample was fully matched to the age of the delinquents of the centers, and the highest frequency was related to the age group of 17 years. That is $58(45.7 \%)$ of the participants were 17 years, $24(18.9 \%)$ were 16 years, $23(8.1 \%)$ were 19 years, $5(3.9 \%)$ were 14 years, and $2(1.6 \%)$ were 13 years old. According to the data, 11( $8.7 \%$ ) were born in villages, 56(44.1\%) were born in small cities, and 60(47.2\%) were born in large cities. Of the current sample, $97(76.4 \%)$ were urban residents, 25(19.7\%) were urban, and 5(3.9\%) were rural residents. In terms of employment status, 102(80.3\%) of the participants left education, while the rest, 25(19.7\%) were still studying. Also, 12(9.6\%) were illiterate, 30 $(23.6 \%)$ were elementary school students, 39(30.7\%) were studying at middle school, and 46(36.2\%) were high school students.
The study showed that $28(22 \%)$ reported their childhood were often infected with conflict and discomfort, $67(52.8 \%)$ reported it normal, and $32(25.2 \%)$ reported to have good family members. Totally, $5(3.9 \%)$ children reported being raised in a family with excellent financial condition, 26(20.5\%) with good condition, 64(50.4\%) with the average condition, and $32(25.2 \%)$ with poor condition. $23(18.1 \%$ ) children reported discrimination in their family, while the remaining $104(81.9 \%)$ children did not complain about that.

Table 2 presents the mean and standard deviation of the scores of the two groups of intervention and control for each principle of the Red Cross and Red Crescent (three principles of humanity, impartiality, and voluntary service), life skills (three skills of self-awareness, problem-solving, and management of anger), and the scale of First Aid.

First, the correlation between variables was investigated, using the Pearson correlation coefficient. There is a positive correlation between all the values. The strongest correlation was between the three principles of the Red Cross (humanity and impartiality: 0.800, humanity, and voluntary service: 0.855 , and voluntary service with impartiality: 0.744). The correlation was higher than 0.730 among the three dimensions of life skills (selfawareness, problem-solving, and anger management). The correlation between dim ensions of life skills and dimensions of fundamental principles was also higher than 0.5 . To test the above hypotheses (separately for each dimension), the t test was used in two independent groups. Previously, the Kolmogorov Smirnov test confirmed the normal distribution of data (Table 3).

\section{Discussion}

The findings show that the fundamental principles of the Red Cross and Crescent in the form of cognitivebehavioral approaches and using the model provided can have a positive effect on the attitude of children and adolescents in conflict with the law. Based on the data in (Table 4), in the pre-test, the mean scores of each fundamental principle (humanity, impartiality, and voluntary service) and the total score were different between the two groups of intervention and control.

This difference can be attributed to accident or sampler matching constraints. In the post-test, the significant difference between the two groups and the difference between the pre-test and post-test scores in the intervention group indicated the effectiveness of the intervention model. In the follow-up test, which was performed 
Table 2. The Mean \pm SD of the variables studied in two study groups

\begin{tabular}{|c|c|c|c|c|c|}
\hline \multirow{2}{*}{ The Test } & \multirow{2}{*}{ Variable } & \multicolumn{4}{|c|}{ No. Mean $\pm S D$} \\
\hline & & \multicolumn{2}{|c|}{ Intervention Group } & \multicolumn{2}{|c|}{ Control Group } \\
\hline \multirow{8}{*}{ Pre-test } & Humanity & 70 & $72.66 \pm 11.73$ & 57 & $67.25 \pm 15.21$ \\
\hline & Impartiality & 70 & $66.08 \pm 13.69$ & 57 & $60.88 \pm 11.85$ \\
\hline & Voluntary service & 70 & $83.45 \pm 11.49$ & 57 & $74.97 \pm 15.94$ \\
\hline & Total & 70 & $76.50 \pm 10.07$ & 57 & $69.60 \pm 12.75$ \\
\hline & Self-awareness skill & 70 & $66.95 \pm 12.64$ & 57 & $64.56 \pm 16.09$ \\
\hline & Problem-solving skill & 70 & $56.90 \pm 13.58$ & 57 & $63.35 \pm 16: 49$ \\
\hline & Anger management skill & 70 & $54.57 \pm 14.60$ & 57 & $60.17 \pm 17.98$ \\
\hline & First aid & 70 & $33.04 \pm 12.16$ & 57 & $24.92 \pm 14.18$ \\
\hline \multirow{8}{*}{ Post-test } & Humanity & 70 & $79.00 \pm 17.55$ & 57 & $64.85 \pm 16.01$ \\
\hline & Impartiality & 70 & $76.19 \pm 17.02$ & 57 & $63.22 \pm 11.23$ \\
\hline & Voluntary service & 70 & $88.04 \pm 13.51$ & 57 & $77.87 \pm 13.45$ \\
\hline & Total & 70 & $82.85 \pm 14.23$ & 57 & $70.97 \pm 12.82$ \\
\hline & Self-awareness skills & 70 & $76.09 \pm 15.48$ & 57 & $68.53 \pm 16.79$ \\
\hline & Problem-solving skill & 70 & $74.36 \pm 18.92$ & 57 & $65.20 \pm 17.74$ \\
\hline & Anger management skill & 70 & $77.38 \pm 17.26$ & 57 & $67.25 \pm 17.76$ \\
\hline & First aid & 70 & $35.88 \pm 16.59$ & 57 & $21.24 \pm 18.04$ \\
\hline \multirow{8}{*}{ Follow-up test } & Humanity & 51 & $75.55 \pm 11.54$ & 23 & $66.95 \pm 9.36$ \\
\hline & Impartiality & 51 & $72.47 \pm 9.63$ & 23 & $57.81 \pm 8.33$ \\
\hline & Voluntary service & 51 & $80.28 \pm 8.91$ & 23 & $73.76 \pm 8.03$ \\
\hline & Total & 51 & $77.19 \pm 7.94$ & 23 & $68.19 \pm 6.28$ \\
\hline & Self-awareness skill & 51 & $74.77 \pm 14.79$ & 23 & $65.94 \pm 13.02$ \\
\hline & Problem-solving skill & 51 & $76.57 \pm 20.61$ & 23 & $71.01 \pm 11.47$ \\
\hline & Anger management skill & 51 & $71.89 \pm 13.16$ & 23 & $67.24 \pm 9.98$ \\
\hline & First aid & 51 & $38.40 \pm 8.18$ & 23 & $31.43 \pm 15.01$ \\
\hline
\end{tabular}

Iranian Rehabilitation Journal

Table 3. Kolmogorov-Smirnov test for normality of variables

\begin{tabular}{cccccccc}
\hline Variables & Humanity & Impartiality & $\begin{array}{c}\text { Voluntary } \\
\text { Service }\end{array}$ & Self-Awareness & $\begin{array}{c}\text { Problem- } \\
\text { Solving }\end{array}$ & Anger Management & First Aid \\
\hline Z statistics & 1.209 & 1.179 & 0.913 & 1.262 & 1.209 & 1.224 & 1.565 \\
$\begin{array}{c}\text { Two-tailed } \\
\text { significance } \\
\text { level }\end{array}$ & 0.107 & 0.055 & 0.375 & 0.083 & 0.077 & 0.100 & 0.115 \\
\hline
\end{tabular}


Table 4. Summary results of t-test for a group of independent variables

\begin{tabular}{|c|c|c|c|c|c|c|}
\hline \multirow{2}{*}{ 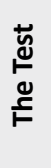 } & \multirow{2}{*}{ Variable } & \multicolumn{2}{|c|}{ Mean \pm SD } & \multicolumn{3}{|c|}{ Statistical Test Results } \\
\hline & & $\begin{array}{l}\text { Intervention } \\
\text { Group }\end{array}$ & Control Group & $\begin{array}{c}\text { Mean } \\
\text { Difference }\end{array}$ & $\begin{array}{l}\text { Significant Difference } \\
\text { Between Two Slopes }\end{array}$ & $\begin{array}{c}\text { Interpretation of } \\
\text { Test }\end{array}$ \\
\hline \multirow{8}{*}{ 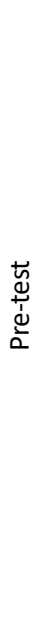 } & Humanity & $72.66 \pm 11.73$ & $67.25 \pm 15.21$ & 5.41 & 0.030 & Significant \\
\hline & Impartiality & $66.08 \pm 13.69$ & $60.88 \pm 11.85$ & 5.20 & 0.024 & Significant \\
\hline & $\begin{array}{l}\text { Voluntary } \\
\text { service }\end{array}$ & $83.45 \pm 11.49$ & $74.97 \pm 15.94$ & 8.48 & 0.001 & Significant \\
\hline & Total & $76.50 \pm 10.70$ & $69.60 \pm 12.75$ & 6.89 & 0.001 & Significant \\
\hline & $\begin{array}{l}\text { Self-awareness } \\
\text { skill }\end{array}$ & $66.95 \pm 12.64$ & $64.56 \pm 16.09$ & 2.39 & 0.362 & Non- significant \\
\hline & $\begin{array}{l}\text { Problem-solv- } \\
\text { ing skills }\end{array}$ & $56.90 \pm 13.58$ & $63.35 \pm 16.49$ & -6.44 & 0.017 & Significant \\
\hline & $\begin{array}{l}\text { Anger manage- } \\
\text { ment skills }\end{array}$ & $54.57 \pm 14.60$ & $60.17 \pm 17.98$ & -5.60 & 0.055 & Non- significant \\
\hline & First aid & $33.04 \pm 12.16$ & $24.92 \pm 14.118$ & 8.07 & 0.001 & Significant \\
\hline \multirow{8}{*}{ 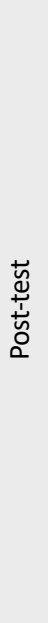 } & Humanity & $79.00 \pm 17.55$ & $64.85 \pm 16.01$ & 14. 14 & 0.000 & Significant \\
\hline & Impartiality & $76.19 \pm 17.02$ & $63.22 \pm 11.23$ & 960.12 & 0.000 & Significant \\
\hline & $\begin{array}{l}\text { Voluntary } \\
\text { service }\end{array}$ & $880.04 \pm 13.51$ & $77.87 \pm 13.45$ & 100.17 & 0.000 & Significant \\
\hline & Total & $820.85 \pm 14.23$ & $70.97 \pm 12.82$ & 11.88 & 0.001 & Significant \\
\hline & $\begin{array}{l}\text { Self-awareness } \\
\text { skill }\end{array}$ & $76.09 \pm 15.48$ & $68.53 \pm 16.79$ & 7.55 & 0.010 & Significant \\
\hline & $\begin{array}{l}\text { Problem-solv- } \\
\text { ing skill }\end{array}$ & $74.36 \pm 18.92$ & $65.20 \pm 17.74$ & 9.16 & 0.006 & Significant \\
\hline & $\begin{array}{l}\text { Anger manage- } \\
\text { ment skill }\end{array}$ & $77.38 \pm 17.26$ & $67.25 \pm 17.76$ & $10: 12$ & 0.002 & Significant \\
\hline & First aid & $35.88 \pm 16.59$ & $21.24 \pm 18.04$ & 14.85 & 0.000 & Significant \\
\hline \multirow{8}{*}{ 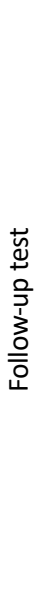 } & Humanity & $75.55 \pm 11.54$ & $66.95 \pm 9.36$ & 8.59 & 0.001 & Significant \\
\hline & Impartiality & $72.47 \pm 9.63$ & $57.81 \pm 8.33$ & 14.66 & 0.000 & Significant \\
\hline & $\begin{array}{l}\text { Voluntary } \\
\text { service }\end{array}$ & $80.28 \pm 8.91$ & $73.76 \pm 8.03$ & 6.52 & 0.004 & Significant \\
\hline & Total & $77.19 \pm 7.94$ & $68.19 \pm 28.6$ & 9.00 & 0.000 & Significant \\
\hline & $\begin{array}{l}\text { Self-awareness } \\
\text { skill }\end{array}$ & $74.77 \pm 14.79$ & $65.94 \pm 13.02$ & 8.82 & 0.016 & Significant \\
\hline & $\begin{array}{l}\text { Problem-solv- } \\
\text { ing skill }\end{array}$ & $76.57 \pm 20.61$ & $71.01 \pm 11.47$ & 5.56 & 0.142 & Non- significant \\
\hline & $\begin{array}{l}\text { Anger manage } \\
\text { ment skill }\end{array}$ & $71.89 \pm 13.16$ & $67.24 \pm 9.98$ & 4.64 & 0.100 & Non- significant \\
\hline & First aid & $38.40 \pm 8.18$ & $31.43 \pm 15.01$ & 6.96 & 0.046 & Significant \\
\hline
\end{tabular}


two weeks after the intervention, the mean differences were still significant in both groups, indicating the stability of the intervention. Although the use of these concepts for this purpose has not been studied so far, the approach and cognitive-behavioral intervention in juvenile detention centers have already been used, and many centers use this method.

Ross and Fabiano have provided evidence that social cognitive failures in many offenders will result in self-regulation of their cognitive transformation levels. Based on an analysis of rehabilitation programs for criminals, they have concluded that the most effective methods are those with a cognitive component [21]. A meta-analysis confirmed this view and proved the effectiveness of most programs with a cognitive component [11]. Consequently, Ross and Fabiano have suggested that the thinking and content ability should be the first objectives of rehabilitation programs, and then they should pursue important goals such as social skills, solving interpersonal problems, cognitive styles, attention to social consequences, critical reasoning, values, metacognition, and self-control.

Abulmaali et al. carried out a research activity, using the cognitive-behavioral approach to improve the social awareness of the delinquents in Rehabilitation and Development Center of Tehran [22]. According to the results of this study, the implementation of the educational program for promoting social cognition of delinquents in social skills, anger control, communication skills, social problem-solving skills, and self-knowledge skills has led to the enhancement of these skills. Various studies have shown that cognitive-behavioral group has considerable effects on improving life skills, reducing stressful responses, effective management of anxiety and depression, reducing panic attacks, and high-risk behaviors, such as drug and alcohol abuse, as well as reducing the severity of unhealthy attitudes in adolescents.

As presented in (Table 4), regarding the basic life skills, the mean scores of self-awareness skill in the pre-test in the two groups did not have a significant difference, but in the post-test and follow-up test, this difference was significant and indicated the effectiveness of the model in improving self-awareness and stability in the intervention group. However, the average score of problem-solving skills in the pre-test was different between the two groups, but it was more significant in the control group. In the post-test, this difference was significant, but in the negative direction, i.e. the intervention group was stronger. Therefore, the model has also been effective in promoting this skill.
The follow-up test showed that this skill reduced two weeks after the intervention, and its stability required repeated intervention. This finding is consistent with other studies in this area. In the anger management skill, the mean scores of the two groups did not show a significant difference, but in the post-test, this difference was significant in favor of the control group and indicated the effectiveness of the model in promoting this skill. In the follow-up test, we also observed a drop in the mean scores of this skill, which meant that the stability of this skill needed more repetition and practice. This phenomenon has also been observed in other studies, including Goldstein et al. study [23].

Ruperto et al. have also examined the effect of life skills training, including social skills on prisoners [18]. In the "Resolve to Stop Violence" project, they trained 101 prisoners in these skills. After their release, it was observed that re-arrest was reduced to $46.3 \%$ in prisoners, who had been trained for at least 8 weeks. This decrease was $53.1 \%$ in prisoners trained 12 weeks and $82.6 \%$ for prisoners trained 16 weeks.

Overall, teaching problem-solving skill seems to be a promising method, since accelerating cognitive transformation will affect other variables, such as applying nongrowth, along with antisocial behaviors [24]. Nemati indicated that 12 training sessions on anger management skills were effective in reducing general aggression and subscales of aggressive thoughts and behavior. These results were repeated in the follow-up every three months [25]. With anger management training based on the cognitive-behavioral approach to institutionalized adolescents, Shakibaei et al. found that the reactive anger and instrumental anger of the treatment group significantly decreased [26]. The proper adaptation of the subjects to the environment and conditions of the institute following the application of anger management group therapy was also reported in this study.

The first aid sector was incorporated into the model for the development of social responsibility and operational functions of the voluntary service sector. According to (Table 4), in the pre-test, the mean scores of the two groups were different, but after the intervention and in the post-test, the significance of the difference in mean indicated that the model was successful in increasing the selfefficacy and heterogeneity of the experimental group. This difference exists after the follow-up period between the two groups and shows that this skill has a good stability.

The goal of many behavioral programs, including SST (student success team), is to increase the competence 
of criminals within the framework of social interaction [14]. The basic assumption is that increasing general or specific skills can help the client avoid further crimes.

Therefore, the designed model using the three basic principles of the Red Cross population, basic life skills, and first aid skills can be effective in changing the attitudes and behavior of the juvenile detention centers. This finding is consistent with the previous studies and similar experiences. In the context of cognitive-behavioral education in improving social cognitive skills, based on a comprehensive meta-analysis, Antonowicz and Ross developed a multifaceted multidimensional program called R \& R in the field of teaching social cognitive skills designed for delinquents [27].

Ross held his training program in 35 sessions ( 70 hours) in a group. His goal was to strengthen the power of reasoning in offenders. The components of his curriculum were self-control, metacognition, social skills, social problem-solving skills, creative thinking, critical thinking, social perspectives, enhancement and improvement of values, and emotional management. The results of his research indicated the effectiveness of educational methods applied to criminals' social cognition.

The findings of a study carried out by LaGrange and Silverman also confirmed the effectiveness of cognitive-behavioral group work on children with an anxiety disorder [28]. The research has also focused on services related to aggressive offender treatment programs in Canada. The program provided 24 hours of group training in 16 weeks, and the content of the program included the effective management of arousal, cognitive retraining, problem-solving, courage, conflict resolution, lifestyle interpretation of risk factors, and increased control. The study found significant results in reducing violence and violent crime.

With reviewing 30 studies on delinquent and aggressive adolescents, Apter and Goldstein found strong evidence of skills acquisition after the end of the course [15]. In a controlled study of young criminals of an institution, Hudson also pointed out that they improved their level of performance in specific skills such as eye contact, head movement, and speech content [13]. However, the ability to maintain skills after the training period was less mentioned, and their generalization varied. Goldstein et al. concluded that, on average, only $15 \%$ to $20 \%$ of people, who have passed social skills training programs, have been able to generalize their learned abilities beyond the educational framework [23]. These authors managed to increase this figure by up to $50 \%$ by implementing a structured training program that incorporated the general principles of learning, training of a wider range of skills, creating diversity in stimuli, and planning natural enhancements.

Also, adolescents usually reduce their social problems; so, since the end of the educational period, some researchers have also achieved a general change in personalities, such as being more under the control of internal power or increasing self-esteem. Goldstein et al. argue that the best solution is that the therapist concentrates on the interpersonal, cognitive, and emotional skills that are essential for compromising with the community [23]. The authors developed the method of "Aggressive Replacement Training" (ART), using a combination of several educational methods. The first results of using this method with prisoners of conscience showed that the ART method leads to promoting skills and reducing arousal, and it gradually creates a better adaptation to the group. Subsequently, the results of the ART method were compared between two educational groups (juvenile offenders group and the youth group with their families) with the status of the control group, who received no treatment.

It was concluded that six months after the start of the program, the frequency of the arrest in the experimental groups was $15 \%$ versus $43 \%$ in the control group. Ghajavand and Hajar Khorush also used the group cognitivebehavioral approach to develop coping skills for preventing recurrence in addicted people [29]. They evaluated this model at a significant level of 0.01 in reducing the recurrence of drug use in the addicts. Also, the results of their quasi-experimental study indicated a significant increase in the utilization of coping strategies in this group. Generally, according to the numerous studies conducted on the cognitive-behavioral interventions and the heterogeneity of criminals, multivariate interventions may be the most appropriate method. Accordingly, the present plan uses a hybrid model for its intervention.

\section{Conclusions}

Based on the study findings, a designed model using three basic principles of society, basic life skills, and first aid skills can be effective in changing the attitudes and behavior of people in the juvenile detention centers. This finding is consistent with the results of similar studies, but requires additional longitudinal studies for its effects on the frequency of recidivism, arrest, trial, and return to the center or imprisonment. 


\section{Ethical Considerations}

\section{Compliance with ethical guidelines}

All of the ethical considerations have been considered in this research.

\section{Funding}

This research was approved and supported by the Iranian Red Crescent society.

\section{Authors' contributions}

Study design: Seyyed Mohammad Hossein Javadi; Literature search and review: Hamed Seddighi; Conduction of the study, data collection: Lotfollah Mohseni, Iraj Esmaili, Ataollah Mohamadi, Seyyed Mohammad Hossein Javadi; Data entry and analysis revision: Seyyed Hadi Mousavi, Seyyed Mohammad Hossein Javadi; Writing, reading, editing, and approving the final version of the manuscript: All authors.

\section{Conflict of interest}

The authors declared no conflict of interest.

\section{Acknowledgments}

The authors acknowledge their gratitude to Iranian Red Crescent Society for all supports from this study.

\section{References}

[1] Seddighi H, Salmani I, Javadi MH, Seddighi S. Child abuse in natural disasters and conflicts: A systematic review. Trauma, Violence, \& Abuse. 2019; 13:1524838019835973. [DOI:10.1177/1524838019835973] [PMID]

[2] Latessa EJ. Effectiveness of cognitive behavioral interventions for youthful offenders: Review of the research (part 2). National Clearinghouse on Homeless Youth \& Families. 2006; 12(3-4):12-3.

[3] Siegel LJ, Senna JJ, Hahn PH. Juvenile delinquency: Theory, practice, and law. Juvenile and Family Court Journal. 1981, 32(4):69-71. [DOI:10.1111/j.1755-6988.1981.tb01255.x]

[4] Andrews DA, Zinger I, Hoge RD, Bonta J, Gendreau P, Cullen FT. A human science approach or more punishment and pessimism: A rejoinder to Lab and Whitehead. Criminology. 1990; 28(3):419-30. [DOI:10.1111/j.1745-9125.1990.tb01332.x]

[5] Bonta J, Jesseman R, Rugge T, Cormier R. Restorative justice and recidivism: Promises made, promises kept. In: Sullivan D, Tifft L, editors. Handbook of Restorative Justice: A Global Perspective. Abingdon-on-Thames: Routledge; 2006.
[6] Siegel LJ, Welsh B, Senna J. Juvenile delinquency: Theory, practice and law. $12^{\text {th }}$ edition. Boston: Cengage Learning, 2006

[7] Chaiken S, Thompson C, Shoemaker W. Mental health interventions in correctional settings. In: Charles L, Scott MD, editors. Handbook of Correctional Mental Health. Washington DC: American Psychiatric Publishing; 2005.

[8] Serin RC. Violent recidivism in criminal psychopaths. Law and Human Behavior. 1996; 20(2):207-17. [DOI:10.1007/ BF01499355]

[9] Seto MC, Barbaree HE. The role of alcohol in sexual aggression. Clinical Psychology Review. 1995; 15(6):545-66. [DOI:10.1016/0272-7358(95)00033-L]

[10] Hanson RK, Gordon A, Harris AJ, Marques JK, Murphy W, Quinsey VL, et al. First report of the collaborative outcome data project on the effectiveness of psychological treatment for sex offenders. Sexual Abuse. 2002; 14(2):169-94. [DOI:10.11 77/107906320201400207] [PMID]

[11] Izzo RL, Ross RR. Meta-analysis of rehabilitation programs for juvenile delinquents: A brief report. Criminal Justice and Behavior. 1990; 17(1):134-42. [DOI:10.1177/0093854890017001 008]

[12] Lösel F, Schmucker M. The effectiveness of treatment for sexual offenders: A comprehensive meta-analysis. Journal of Experimental Criminology. 2005; 1(1):117-46. [DOI:10.1007/ s11292-004-6466-7]

[13] Hudson DL. Juvenile justice. New York: Infobase Publishing; 2010.

[14] Hollin CR, Trower P. Handbook of social skills training. Oxford: Pergamon; 1986.

[15] Apter SJ, Goldstein AP. Youth violence: Programs \& prospects. New York: Pergamon Press; 1986.

[16] Cullen FT, Golden KM, Cullen JB. Is child saving dead? Attitudes toward juvenile rehabilitation in Illinois. Journal of Criminal Justice. 1983; 11(1):1-13. [DOI:10.1016/00472352(83)90093-4

[17] Silverman WK, Kurtines WM, Ginsburg GS, Weems CF, Lumpkin PW, Carmichael DH. Treating anxiety disorders in children with group cognitive-behavioral therapy: A randomized clinical trial. Journal of Consulting and Clinical Psychology. 1999; 67(6):995-1003. [DOI:10.1037/0022 006X.67.6.995] [PMID]

[18] Ruperto N, Nikishina I, Pachanov ED, Shachbazian Y Prieur AM, Mouy R, et al. A randomized, double-blind clinical trial of two doses of meloxicam compared with naproxen in children with juvenile idiopathic arthritis: Short-and longterm efficacy and safety results. Arthritis \& Rheumatology. 2005; 52(2):563-72. [DOI:10.1002/art.20860] [PMID]

[19] Pearson FS, Lipton DS, Cleland CM, Yee DS. The effects of behavioral/ cognitive-behavioral programs on recidivism Crime \& Delinquency. 2002; 48(3):476-96. [DOI:10.1177/0011 128702048003006]

[20] Lipsey MW, Landenberger NA, Wilson SJ. Effects of cognitive-behavioral programs for criminal offenders. Campbel Systematic Reviews. 2007; 3(1):1-27. [DOI:10.4073/csr.2007.6] 
[21] Ross RR, Fabiano EA. Time to think: A cognitive model of delinquency prevention and offender rehabilitation. Tennessee: Institute of Social Sciences and Arts; 1985.

[22] Abolmalali Alhosseini Kh, Mehran G, Monadi M, Khosravi Z, Nazerzadeh Kermani F. [The effect of cognitive-behavioral education method on the promotion of some components of social cognition of boy criminals (Persian)]. Psychological Studies. 2009; 5(2):45-71.

[23] Goldstein NE, Arnold DH, Weil J, Mesiarik CM, Peuschold D, Grisso T, et al. Comorbid symptom patterns in female juvenile offenders. International Journal of Law and Psychiatry. 2003; 26(5):565-82. [DOI:10.1016/S0160-2527(03)00087-6]

[24] Kazdin AE. Treatment of antisocial behavior in children: Current status and future directions. Psychological Bulletin. 1987; 102(2):187-203. [DOI:10.1037/0033-2909.102.2.187] [PMID]

[25] Nemati N. [The effectiveness education skills control and management anger in reducing aggression among male prisoners (Persian)]. Correction and Education. 2009; 86(7):48-54.

[26] Shakibaei F, Shahrivar Z, Asaari S. [Anger management group therapy with cognitive behavior approach in institution adolescents (Persian)]. Advances in Cognitive Science. 2004; 6(1-2):59-66

[27] Antonowicz DH, Ross RR. Social problem-solving deficits in offenders. In: McMurran M, McGuire J. Social Problem Solving and Offending: Evidence, Evaluation and Evolution. Hoboken: John Wiley \& Sons Ltd; 2005. [DOI:10.1002/9780470713488.ch5]

[28] LaGrange TC, Silverman RA. Low self-control and opportunity: Testing the general theory of crime as an explanation for gender differences in delinquency. Criminology. 1999; 37(1):41-72. [DOI:10.1111/j.1745-9125.1999.tb00479.x]

[29] Ghajavand KY, Hajar khorush M. [Review the effect partly worker a group to the way cognitive- behavioral at development skills coping and prevention from recurrence at persons addicted (Persian)]. Paper Presented at: $3^{\text {rd }}$ Congress National Advice. 20 March 2012; Khomeini Shahr, Iran. 
This Page Intentionally Left Blank 